\title{
SOME GENERA AND SPECIES OF THE ASTERINIDAE.
}

By

\author{
Arthur A. Livingstone, \\ (Assistant Zoologist, the Australian Museum, Sydney.)
}

(Plates i-v.)

THIs contribution contains descriptions of seven new species and one new genus, discussions on the grouping of various species within the family, notes on the status of Habroporina pulchella $\mathrm{H}$. L. Clark, and opinions on the validity of the sub-family Tremasterinae.

All the specimens referred to herein are housed in the Australian Museum, Sydney, unless stated to the contrary.

\section{Asterina scobinata sp. nov.}

(Pl. v, figs 9-12, and 15.)

Description.-Body moderately and evenly elevated. Rays five, tapering evenly from the disc and terminating fairly acutely. $R .=11 \mathrm{~mm} ., \mathrm{r} .=6 \mathrm{~mm}$.; R. $=1.8 \mathrm{r}$. Interbrachial arcs angular, fairly acute.

The abactinal plates are regularly arranged, crescentic, imbricated, and of more or less even size. Those on each midradial region form a distinct area of three longitudinal rows. These plates are slightly larger than their neighbours, less crescentic, and overlap one another edgeways to a greater degree.

Low down near the margin in the inter-radial region the abactinal plates are nearly circular, not crescentic, and only slightly imbricated. The raised crescentic surface of each abactinal plate does not lie at an angle; it stands straight and upright, and is armed with a large number of delicate minute spinelets, about ten to twenty in number according to the size of the crescentic surface to be covered. These spinelets, being very small and delicate, are easily dislodged when the specimen is handled. In two of the three specimens before me the spinelets have almost disappeared, leaving a somewhat bare abactinal surface.

The madreporite is very small, almost central in position and porous, not striated or channelled.

The terminal plate is relatively small and usually bare.

The papular pores are numerous, well developed and situated in the notched or crescentic upper surface of the abactinal plates. About twelve series of papular pores occur at the base of each ray. Five to six median series extend from the disc towards the terminal plate, but terminate just before that structure is reached. The centre of the disc, which contains few papular pores, is enclosed by a ring formed by a number of large crescentic plates from which radiate five short and non-perforate inter-radial bands. These bands more or less isolate the pores on the disc and rays so as to create five separate areas.

Twenty-five to twenty-seven superomarginal plates occur on each side of a ray. They are regularly arranged, round, with elevated dome-like centres, a little larger than most abactinal plates in the immediate vicinity, and armed with a circular tuft of delicate spinelets similar in character to those occurring on adjacent abactinal plates. The inferomarginal plates about equal the superomarginals in number. They project outward beyond the superomarginals for some

*12288-A 